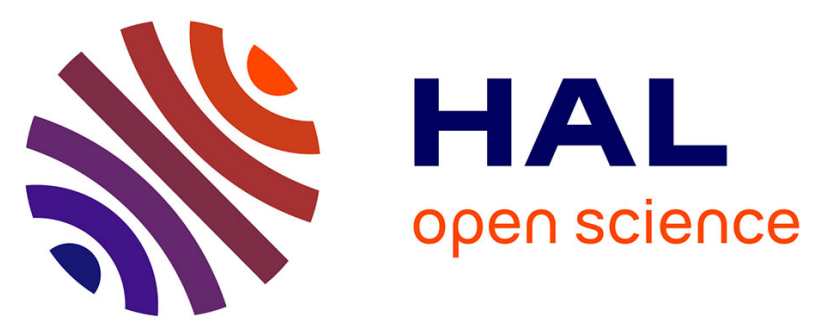

\title{
Optimal multi-model control for nonlinear systems with parametric uncertainties -Diesel Engine case study
}

\author{
Mihaela Ancuţa Mone, Sette Diop, Dumitru Popescu
}

\section{To cite this version:}

Mihaela Ancuţa Mone, Sette Diop, Dumitru Popescu. Optimal multi-model control for nonlinear systems with parametric uncertainties -Diesel Engine case study. 24th International Conference on System Theory, Control and Computing, October 2020, Sinaia, Romania, Oct 2020, Sinaia, Romania. hal-03087436

\section{HAL Id: hal-03087436 https://hal.science/hal-03087436}

Submitted on 23 Dec 2020

HAL is a multi-disciplinary open access archive for the deposit and dissemination of scientific research documents, whether they are published or not. The documents may come from teaching and research institutions in France or abroad, or from public or private research centers.
L'archive ouverte pluridisciplinaire HAL, est destinée au dépôt et à la diffusion de documents scientifiques de niveau recherche, publiés ou non, émanant des établissements d'enseignement et de recherche français ou étrangers, des laboratoires publics ou privés. 


\title{
Optimal multi-model control for nonlinear systems with parametric uncertainties - Diesel Engine case study*
}

\author{
Mihaela-Ancuta Mone ${ }^{1}$ Sette Diop ${ }^{2}$ Dumitru Popescu ${ }^{3}$
}

\begin{abstract}
The paper proposes a novel solution to control the combustion regime of Diesel engines in order to obtain NOx reduction and to minimize fuel consumption. The nonlinear dynamic model associated to a Diesel platform equipped with an EGR and VGT is estimated. The linearized and reduced state model structure has been approximated. The optimal control procedure for the air flow in the intake manifold of the cylinders and the pressure inside the combustion chamber of the Diesel engine is proposed. A multi-model control for nonlinear systems with parametric uncertainties solution is developed. Our procedure is implying the minimization of the multi-model structure by reducing the identification effort of the number of models and associated controllers. The simulation results will be implemented and validated on the experimental Diesel engine.
\end{abstract}

\section{INTRODUCTION}

The Diesel engine is widely embarked on vans, tractors, tube, motorcycles, underwater and ships. The majority of vehicles are powered by Diesel. A 200 years old invention became the most important engine of the 21st century. Throughout the years, many analyses have been performed as to whether the utilization of Diesel engines is dangerous for the human health or not in terms of pollution. As to reduce the negative impact of the Diesel engines on human's health and environment pollution, we want to obtain the NOx reduction and the reduction of the consumed fuel by these engines [1].

Section II presents the mathematical models associated to the dynamic the experimental Diesel engine. The data was obtained on the experimental platform located at the University Picardie in Amiens, France [3]. The engine is equipped with an exhaust gas recirculation system and a variable geometry turbocharger. The models presented here are as follows: state-space model with linear parametervarying, invariant model, reduced invariant model. Given the difficulties to access the parameters of the invariant model, the system has been decoupled and we have considered the direct transfer from the most two important inputs of the system to the outputs. Therefore, section II-D presents the input/output engine models, for which state-space minimal realizations are presented in II-E. For the latter, LQR control law is discussed in section III.

\footnotetext{
*The work has been funded by the Operational Programme Human Capital of the Ministry of European Funds through the Financial Agreement 51675/09.07.2019, SMIS code 125125

${ }^{1}$ Mihaela-Ancuta Mone is with Faculty of Automatic Control and Computers, University Politehnica of Bucharest, Romania mihaela.monedstud. acs . upb.ro

${ }^{2}$ Sette Diop, with Laboratoire des Signaux \&
Systemes, CentraleSupelec, Gif sette.diopal2s.centralesupelec.fr

${ }^{3}$ Dumitru Popescu, with with Faculty of Automatic Control and Computers, University Politehnica of Bucharest, Romania dumitru.popescu@acse.pub.ro
}

Section IV includes a robustness analysis regarding the parametric uncertainties of the models concerning the LQR control. The structural deviations of the command have been obtained so that the closed-loop system remains stable. Three operating points have been proposed on the non-linear characteristic so that the commutation mechanism of the multi-model control is improved.

The results obtained in simulation and the corresponding analysis results are listed in section V.

\section{ENGINE'S DYNAMIC MODELS}

\section{A. State-space model with linear parameter-varying}

Starting from the following linear parameter-varying model:

$$
\left\{\begin{array}{l}
\dot{x}(t)=\mathbf{A}(\rho(t)) x(t)+\mathbf{B}(\rho(t)) u(t) \\
y(t)=\mathbf{C}(\rho(t)) x(t)+\mathbf{D}(\rho(t)) u(t)
\end{array}\right.
$$

where the non-linear matrices $\mathbf{A}, \mathbf{B}, \mathbf{C}$ and $\mathbf{D}$ depend on $\rho(t)$, an unknown exogenous time-varying parameter, we want to acquire a reduced order model, but whose approximation is to be counteracted by the control laws designed later.

The mathematical model of the engine is obtained working on the general gas equation:

$$
p V=\nu R T
$$

where $\nu$ is the amount of substance present in a tube of volume $V$, pressure $p$ and the temperature $T . R$ is the ideal gas constant $\left(R=8.314 \frac{\mathrm{J}}{\mathrm{molK}}\right)$.

We apply the time derivative on equation (2) and write one differential equation for the intake and one for the exhaust. We obtain the dynamic of the system:

$$
\begin{gathered}
\dot{p_{i}}=\frac{R T_{i}}{V_{i}}\left(W_{c i}+F_{i e}\right)+\frac{\dot{T}_{i}}{T_{i}} p_{i} \\
\dot{p_{x}}=\frac{R T_{x}}{V_{x}}\left(F_{i c}+F_{f}-F_{x i}-F_{x t}\right)+\frac{\dot{T}_{x}}{T_{x}} p_{x} \\
\dot{P}_{c}=\frac{1}{\tau}\left(-P_{c}+P_{t}\right)
\end{gathered}
$$

where $p_{i}$ is the intake manifold pressure, $p_{x}$ is the exhaust manifold pressure, (5) is the dynamic of the turbocharger'given by the power transfer delayed by $\tau$.

By considering the temperatures in the intake manifold and exhaust manifold at a constant value, the effect of the variables $\dot{T}_{i}, \dot{T}_{x}, p_{i}$ and $p_{x}$ is not important, and we obtain the first approximation of the non-linear model (3) - (5).

Using the flow rate formula, we have determined the EGR flow rate(i.e. $F_{x i}$ ) and the VGT flow rate (i.e. $F_{x t}$ ). The variation of the air flow inside the intake manifold to the cylinders (i.e. $F_{i e}$ ) was determined based on the speed density equation. 
We consider the parameters of the flow inside the VGT (i.e. $F_{x t}$ ) at a constant value, and also the temperatures inside the intake and exhaust manifolds, $T_{i}$ and $T_{x}$, respectively. Therefore, we can say that (3) - (5) have constant parameters [2]. This new model approximation does not affect the engine's dynamics at low and medium engine speed even though, in reality, these parameters vary based on the operating point.

\section{B. Invariant model}

The following state-space model, i.e. the invariant model, is obtained based on (3) - (5):

$$
\left\{\begin{array}{c}
\left(\begin{array}{c}
\dot{p}_{i} \\
\dot{p}_{x} \\
\dot{P}_{c}
\end{array}\right)=\mathbf{A}\left(\begin{array}{c}
p_{i} \\
p_{c} \\
P_{c}
\end{array}\right)+\mathbf{B}\left(\begin{array}{c}
A_{r} \\
x_{v} \\
N \\
W_{f}
\end{array}\right) \\
\left(\begin{array}{c}
W_{c i} \\
p_{i}
\end{array}\right)=\mathbf{C}\left(\begin{array}{c}
p_{i} \\
p_{x} \\
P_{c}
\end{array}\right)+\mathbf{D}\left(\begin{array}{c}
A_{r} \\
x_{v} \\
N \\
W_{f}
\end{array}\right)
\end{array}\right.
$$

The inputs are represented by the position of the VGT valve, $A_{r}$, the position of the EGR valve, $x_{v}$, the engine speed, $N$, and the fuel flow, $W_{f}$. The outputs are the mass air flow, $W_{c i}$, and the manifold absolute pressure, $p_{i}$. The states are given by $p_{i}, p_{x}$ and $P_{C}$. The matrices $\mathbf{A}, \mathbf{B}, \mathbf{C}$ and $\mathbf{D}$ have corresponding dimensions, and $\mathbf{D}$ is the null matrix. Therefore, we have a three-order model.

\section{Reduced invariant model}

We considered the following approximation in order to reduce the model given by (6), meaning following two inputs were redefined as below:

$$
\left\{\begin{array}{l}
A_{r}=\overline{A_{r}}+8.9 * 10^{-5}\left[\mathrm{~m}^{2}\right] \\
x_{v}=x_{v}+0.5
\end{array}\right.
$$

The values of the fuel flow $W_{f}$ and the engine speed $N$ are considered constant.

Reducing the number of inputs from four to two, the following state-space representation has been obtained:

$$
\left\{\begin{array}{l}
\left(\begin{array}{c}
\dot{p}_{i} \\
\dot{p}_{x} \\
\dot{P}_{c}
\end{array}\right)=\mathbf{A}\left(\begin{array}{c}
p_{i} \\
p_{c} \\
P_{c}
\end{array}\right)+\mathbf{B}\left(\begin{array}{c}
A_{r} \\
x_{v}
\end{array}\right) \\
\left(\begin{array}{c}
W_{c i} \\
p_{i}
\end{array}\right)=\mathbf{C}\left(\begin{array}{c}
p_{i} \\
p_{x} \\
P_{c}
\end{array}\right)
\end{array}\right.
$$

where each element of the matrices $\mathbf{A}, \mathbf{B}$ and $\mathbf{C}$ are identified using (3) - (5).

\section{Input/Output Models}

It is difficult to access the parameters of the invariant model, therefore we decouple the system (6) and consider the direct transfer from the EGR to $p_{i}$ and VGT to $W_{c i}$, respectively. Through model identification, using the recursive least squares method on the data acquired on the experimental Diesel platform, we obtain the input/output models of the two systems.
1) Multi-models associated to the EGR-p $p_{i}$ transfer: The discrete transfer function from $A_{r}$ to the pressure $p_{i}$ is:

$$
\mathbf{H}_{d_{A_{r}-p_{i}}}(z)=\frac{280.8 z^{3}-102.9 z^{2}-273.6 z-99.22}{z^{3}-2.271 z^{2}+1.617 z-0.3458}
$$

The choice of operating points has been made based on the non-linear characteristic of the EGR valve. Therefore, the operating domain has been split into three ranges, corresponding to the movement of the EGR valve: $20-40 \%$, 40$60 \%$ and $60-80 \%$ opening.

Therefore, we have the following three dynamic models:

$$
\begin{gathered}
\mathbf{H}_{d_{1} A_{r}-p_{i}}(z)=\frac{280.8 z^{3}-102.9 z^{2}-273.6 z-99.22}{z^{3}-2.271 z^{2}+1.617 z-0.3458} \\
\mathbf{H}_{d_{2} A_{r}-p_{i}}(z)=\frac{210 z^{3}-56.8 z^{2}-198.45 z-77.28}{z^{3}-2.271 z^{2}+1.617 z-0.3458} \\
\mathbf{H}_{d_{3} A_{r}-p_{i}}(z)=\frac{178.5 z^{3}-12.7 z^{2}-102.33 z-24.44}{z^{3}-2.271 z^{2}+1.617 z-0.3458}
\end{gathered}
$$

2) Multi-models associated to the VGT- $W_{c i}$ transfer: The discrete transfer function from $x_{v}$ to the air mass flow $W_{c i}$ is:

$$
\begin{aligned}
\mathbf{H}_{d x_{v}-W_{c i}}(z) & =\frac{0.03711^{3}-0.0785 z^{2}}{z^{3}-2.271 z^{2}+1.617 z-0.3458}+ \\
& +\frac{0.09375 z+0.02185}{z^{3}-2.271 z^{2}+1.617 z-0.3458}
\end{aligned}
$$

The choice of operating points has been made based on the non-linear characteristic of the VGT valve. Therefore, the operating domain has been split into three ranges, corresponding to the movement of the VGT valve: $0-40 \%, 40-60 \%$ and $60-100 \%$ opening.

Therefore, we have the following three liniarized dynamic models:

$$
\begin{aligned}
\mathbf{H}_{d M_{1} x_{v}-W_{c i}}(z) & =\frac{0.03711 z^{3}-0.0785 z^{2}}{z^{3}-2.271 z^{2}+1.617 z-0.3458}+ \\
& +\frac{0.09375 z+0.02185}{z^{3}-2.271 z^{2}+1.617 z-0.3458}
\end{aligned}
$$

$$
\begin{aligned}
\mathbf{H}_{d M_{2} x_{v}-W_{c i}}(z) & =\frac{0.02899 z^{3}-0.0622 z^{2}}{z^{3}-2.271 z^{2}+1.617 z-0.3458}+ \\
& +\frac{0.08945 z+0.01765}{z^{3}-2.271 z^{2}+1.617 z-0.3458}
\end{aligned}
$$

$$
\begin{aligned}
\mathbf{H}_{d M_{3} x_{v}-W_{c i}}(z) & =\frac{0.02489 z^{3}-0.0558 z^{2}}{z^{3}-2.271 z^{2}+1.617 z-0.3458}+ \\
& +\frac{0.08012 z+0.01247}{z^{3}-2.271 z^{2}+1.617 z-0.3458}
\end{aligned}
$$

\section{E. State-space minimal realization}

If we apply $z$-transform to the discrete-time LTI state space model given by (1) and assume that the initial condition of the system $x_{0}=0$, we obtain the next connection between the input and the output of the system:

$$
\mathbf{Y}(z)=\mathbf{H}(z) \mathbf{U}(z)
$$


The transfer function $\mathbf{H}$ of the system is given by:

$$
\mathbf{H}(z)=\mathbf{C}(z \mathbf{I}-\mathbf{A})^{-1} \mathbf{B}+\mathbf{D}
$$

For a SISO transfer function of a LTI system with $b_{0}$ normalized to 1 ,

$$
\mathbf{H}(z)=\frac{b_{1} z^{n-1}+\cdots+b_{n}}{z^{n}+a_{2} z^{n-1}+\cdots+a_{n+1}}
$$

an equivalent state-space representation is given by the matrices $(\mathbf{A}, \mathbf{B}, \mathbf{C}, \mathbf{D})$ whose elements are:

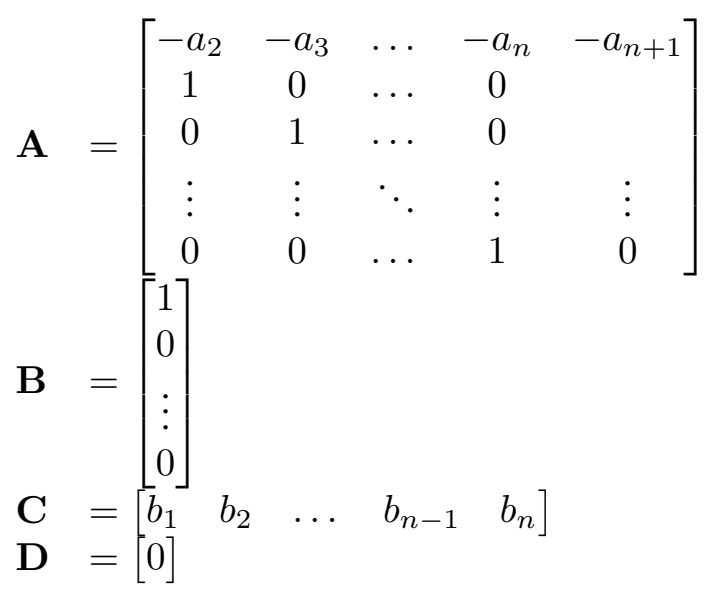

Therefore, for each I/O model presented in II-D we can obtain the corresponding state-space minimal realization.

\section{LINEAR-QUADRATIC REGULATOR}

The solution of the LQR control law is the command matrix $\mathbf{K}_{\mathbf{L Q R}}$ so that the command:

$$
\begin{aligned}
& u=-\mathbf{K}_{L Q R} x \\
& \mathbf{K}_{L Q R}=\mathbf{R}^{-1} \mathbf{B}^{T} \mathbf{P}
\end{aligned}
$$

minimizes the quadratic cost function:

$$
J=\int_{t=0}^{\infty}\left(x^{\top} \mathbf{Q} x+u^{\top} \mathbf{R} u\right) d t
$$

$\mathbf{P}$ from (21) is the solution of the continuous time Riccati differential equation:

$$
\mathbf{A}^{T} \mathbf{P}+\mathbf{P A}-\mathbf{P B R}^{-1} \mathbf{B}^{T} \mathbf{P}+\mathbf{Q}=0
$$

Hence, for the three models corresponding to the three operating points described in II-D, we obtain a corresponding command matrix that ensures the closed-loop stability of the two systems.

\section{Multi-MODEL CONTROL}

The multi-model control structure for the three operating points can be observed in Fig. 1 (adapted from [4]), where $r$ is the set-point, $M_{i}$ represent the models for different operating points $r_{i} . P$ is the process to be controlled, $C_{i}$ represent the controllers, $u_{i}$ represent the commands, $y$ is the process output, $y_{i}$ represent the models output, $e_{i}$ is the model error, $S W I T C H$ is the commutation law, $i=1 . .3$.

In order to improve the commutation between the control algorithms, we propose a robustness analysis of the LQR command designed in III. In [5] is presented an approach towards non-structural parametric uncertainties bounded by norm.
For the state-space models presented in (6) and (8), we consider the following uncertainty model:

$$
\dot{x}(t)=(\mathbf{A}+\Delta \mathbf{A}(t)) x(t)+(\mathbf{B}+\Delta \mathbf{B}(t)) u(t)
$$

where $\Delta \mathbf{A}(t)$ and $\Delta \mathbf{B}(t)$ represent the parametric uncertainties that affect the matrices $\mathbf{A}$ and $\mathbf{B}$, respectively.

There is defined the uncertainty domain, $D_{1}$ :

$$
\begin{aligned}
D_{1}= & \{\Delta \mathbf{A}(t), \Delta \mathbf{B}(t) \mid \\
& \left.\Delta \mathbf{A}^{T}(t) \Delta \mathbf{A}(t) \leq \gamma_{a} \mathbf{Q}_{0}, \Delta \mathbf{B}(t) \leq \gamma_{b} \mathbf{R}_{0}\right\}
\end{aligned}
$$

where $\mathbf{Q}_{0}$ and $\mathbf{R}_{0}$ are symmetric positive definite matrices and $\gamma_{a}$ and $\gamma_{b}$ are positive scalars.

The problem of interest is to find the maximum value of the scalars $\gamma_{a}$ and $\gamma_{b}$ so that the closed-loop system in (24)(25) is stable given the control law (21)-(23) developed for the nominal system.

$\mathbf{Q}$ and $\mathbf{R}$ are defined as follows:

$$
\begin{aligned}
& \mathbf{Q}=\mathbf{Q}_{0}+\mathbf{Q}_{1} \\
& \mathbf{R}=\mathbf{R}_{0}+\mathbf{R}_{1}
\end{aligned}
$$

[5] provides the theorem according to which the closedloop uncertain system (24)-(25) with the control law (21)(23) is stable within the domain $D_{1}$ which satisfies:

$$
\gamma \mathbf{I}=\left(\gamma_{a}+\gamma_{b}\right) \mathbf{I}<\Gamma
$$

where

$$
\Gamma=\mathbf{P}^{-1}\left(\mathbf{Q}_{1}+\mathbf{K}_{L Q R}^{T} \mathbf{R}_{1} \mathbf{K}_{L Q R}\right) \mathbf{P}^{-1}
$$

is a symmetric positive definite matrix. The control law is developed on the nominal system using the standard LQ criteria. The uncertainties are taken into account through the control matrices (26) and (27). The theorem gives the possible upper bound of the uncertainties that are rendering unstable the closed-loop system.

Our procedure is implying the minimization of the multimodel structure by reducing the identification effort of the number of models and associated controllers. By enlarging the domain of uncertainties, we obtain the reduction of (model, controller) pairs in the proposed structure [14].

In other words, we have to determine the maximum values of $\Delta \mathbf{A}$ and $\Delta \mathbf{B}$ so that the closed-loop system in (24)-(25) is stable given the LQR control law (21)-(23) developed for the nominal system.

\section{Simulation RESUlts}

The results presented in this section correspond to the reduced invariant model discussed in II-C.

\section{A. Input/Output models simulation}

Using the Matlab environment, the following minimal state-space realizations were obtained.

Therefore, for the transfer function in (9), we obtained:

$$
\begin{aligned}
\mathbf{A}_{p_{i}} & =\left[\begin{array}{ccc}
2.271 & -1.617 & 0.3458 \\
1 & 0 & 0 \\
0 & 1 & 0
\end{array}\right] \\
\mathbf{B}_{p_{i}} & =\left[\begin{array}{l}
1 \\
0 \\
0
\end{array}\right] \\
\mathbf{C}_{p_{i}} & =\left[\begin{array}{lll}
534.8 & -727.7 & -2.119
\end{array}\right] \\
\mathbf{D}_{p_{i}} & =[0]
\end{aligned}
$$


For the transfer function in (13), we obtained:

$$
\begin{aligned}
& \mathbf{A}_{W_{c i}}=\left[\begin{array}{ccc}
2.271 & -1.617 & 0.3458 \\
1 & 0 & 0 \\
0 & 1 & 0
\end{array}\right] \\
& \mathbf{B}_{W_{c i}}=\left[\begin{array}{l}
1 \\
0 \\
0
\end{array}\right] \\
& \mathbf{C}_{W_{c i}}=\left[\begin{array}{lll}
0.0058 & 0.0337 & 0.0347
\end{array}\right] \\
& \mathbf{D}_{W_{c i}}=[0]
\end{aligned}
$$

For each transfer function in (10)-(12) and (14)-(16), respectively, the following minimal realizations were computed:

$$
\begin{aligned}
\mathbf{A}_{1 p_{i}} & =\left[\begin{array}{ccc}
2.271 & -1.617 & 0.3458 \\
1 & 0 & 0 \\
0 & 1 & 0
\end{array}\right] \\
\mathbf{B}_{1 p_{i}} & =\left[\begin{array}{l}
1 \\
0 \\
0
\end{array}\right] \\
\mathbf{C}_{1 p_{i}} & =\left[\begin{array}{lll}
534.8 & -727.7 & -2.119
\end{array}\right] \\
\mathbf{D}_{1 p_{i}} & =[0] \\
\mathbf{A}_{2 p_{i}} & =\left[\begin{array}{ccc}
2.271 & -1.617 & 0.3458 \\
1 & 0 & 0 \\
0 & 1 & 0
\end{array}\right] \\
\mathbf{B}_{2 p_{i}} & =\left[\begin{array}{l}
1 \\
0 \\
0
\end{array}\right] \\
\mathbf{C}_{2 p_{i}} & =\left[\begin{array}{lll}
420.11 & -538.02 & -4.662
\end{array}\right] \\
\mathbf{D}_{2 p_{i}} & =\left[\begin{array}{ll}
0
\end{array}\right]
\end{aligned}
$$$$
\begin{aligned}
\mathbf{A}_{3 p_{i}} & =\left[\begin{array}{ccc}
2.271 & -1.617 & 0.3458 \\
1 & 0 & 0 \\
0 & 1 & 0
\end{array}\right] \\
\mathbf{B}_{3 p_{i}} & =\left[\begin{array}{l}
1 \\
0 \\
0
\end{array}\right] \\
\mathbf{C}_{3 p_{i}} & =\left[\begin{array}{lll}
392.6735 & -390.9645 & 37.2853
\end{array}\right] \\
\mathbf{D}_{3 p_{i}} & =[0]
\end{aligned}
$$

$$
\begin{aligned}
& \mathbf{A}_{1 W_{c i}}=\left[\begin{array}{ccc}
2.271 & -1.617 & 0.3458 \\
1 & 0 & 0 \\
0 & 1 & 0
\end{array}\right] \\
& \mathbf{B}_{1 W_{c i}}=\left[\begin{array}{l}
1 \\
0 \\
0
\end{array}\right] \\
& \mathbf{C}_{1 W_{c i}}=\left[\begin{array}{lll}
0.005777 & 0.03374 & 0.03468
\end{array}\right] \\
& \mathbf{D}_{1 W_{c i}}=[0]
\end{aligned}
$$

$$
\begin{aligned}
& \mathbf{A}_{2 W_{c i}}=\left[\begin{array}{ccc}
2.271 & -1.617 & 0.3458 \\
1 & 0 & 0 \\
0 & 1 & 0
\end{array}\right] \\
& \mathbf{B}_{2 W_{c i}}=\left[\begin{array}{l}
1 \\
0 \\
0
\end{array}\right] \\
& \mathbf{C}_{2 W_{c i}}=\left[\begin{array}{lll}
0.0036363 & 0.04257 & 0.02768
\end{array}\right] \\
& \mathbf{D}_{2 W_{c i}}=[0]
\end{aligned}
$$

$$
\begin{aligned}
& \mathbf{A}_{3 W_{c i}}=\left[\begin{array}{ccc}
2.271 & -1.617 & 0.3458 \\
1 & 0 & 0 \\
0 & 1 & 0
\end{array}\right] \\
& \mathbf{B}_{3 W_{c i}}=\left[\begin{array}{l}
1 \\
0 \\
0
\end{array}\right] \\
& \mathbf{C}_{3 W_{c i}}=\left[\begin{array}{lll}
0.0007252 & 0.039873 & 0.021077
\end{array}\right] \\
& \mathbf{D}_{3 W_{c i}}=[0]
\end{aligned}
$$

The step response of (30) can be observed in Fig. 2 and the step response of (31) can be observed in Fig. 3.

For the multi-model approach, the state-space minimal realizations step response of (10)-(12) are plotted in Fig. 4.

In the case of the multi-model approach, the state-space minimal realizations step response of (14)-(16) can be observed in Fig. 5.

\section{B. Optimal control}

The step response for the closed-loop systems can be observed in Fig. 6.

\section{CONCLUSIONS AND PERSPECTIVES}

The paper presents the dynamic of an experimental Diesel engine. Minimal realizations for the linearized input/output transfer functions for both EGR and VGT were proposed.

A LQR control procedure controls the air flow inside the VGT and the pressure inside the EGR, both systems being present on the experimental platform. A robustness analysis for the LQR command has been performed.

A multi-model structure is proposed and for the LQ control law the upper bound of the non-structural uncertainties are computed so that the closed-loop system remains stable. The commutation problem between the models is addressed using the previous mentioned approach regarding the non-structural uncertainties bounded by norm. Therefore, three operating points have been proposed on the non-linear characteristic and the commutation of the command has been improved.

The stability of the closed-loop system with structural uncertainties can be addressed as further research.

\section{ACKNOWLEDGMENT}

The work has been funded by the Operational Programme Human Capital of the Ministry of European Funds through the Financial Agreement 51675/09.07.2019, SMIS code 125125

\section{REFERENCES}

[1] M-A. Mone, S. Diop, D. Popescu, "Optimal Control for Diesel Engine Combustion Regime“, 22nd International Conference on Control Systems and Computer Science (CSCS), 2019.

[2] S. Cirstoiu, D. Popescu, O. Pages, "MultiModel Adaptive Control for Turbocharged Diesel Engines“, Proceedings of the 1st ICSCS International Conference, Villeneuve dAscq, France, IEEE, 2012.

[3] S. Cirstoiu and D. Popescu, "Multi-model adaptive control for turbocharged Diesel engines“, UPB Scientific Bulletin 2013, Seria C, vol. 75, nr.1, ISSN 1454-234x, pp. 59-68.

[4] C. Lupu, D. Popescu, C. Petrescu, Al. Ticlea, C. Dimon, A. Udrea, I. Bogdan, "Multiple-Model Design and Switching Solution for Nonlinear Processes Control“, ISC'08, The 6th Annual Industrial Simulation Conference, Lyon, France, pp. 71-76, ISBN 978-90-77381-4-03, 2008.

[5] G. Dauphin-Tanguy, L. Foulloy, D. Popescu, "Modelisation, Identification et Commande des Systemes“, Ed. Academiei Romane, Bucuresti, Romania, 2004 


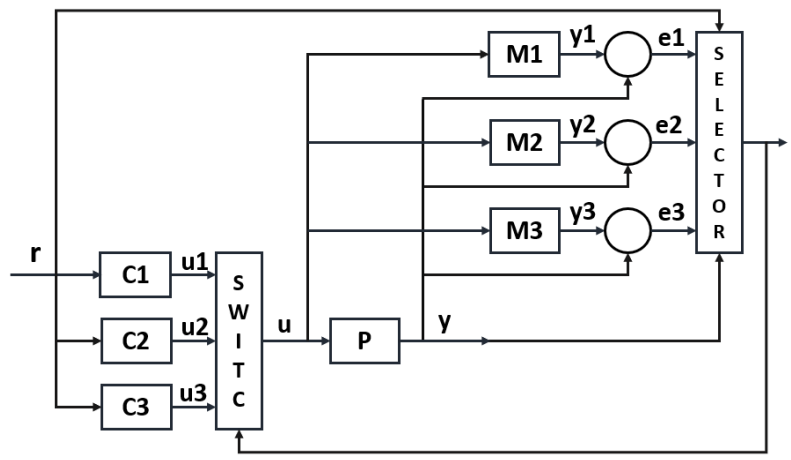

Fig. 1. Multi-model control structure

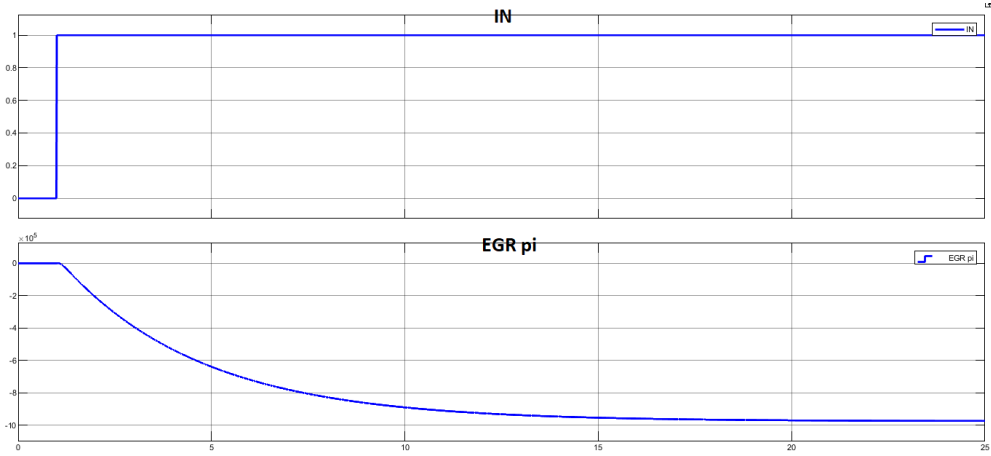

Fig. 2. Minimal realization of EGR- $p_{i}$ transfer step response

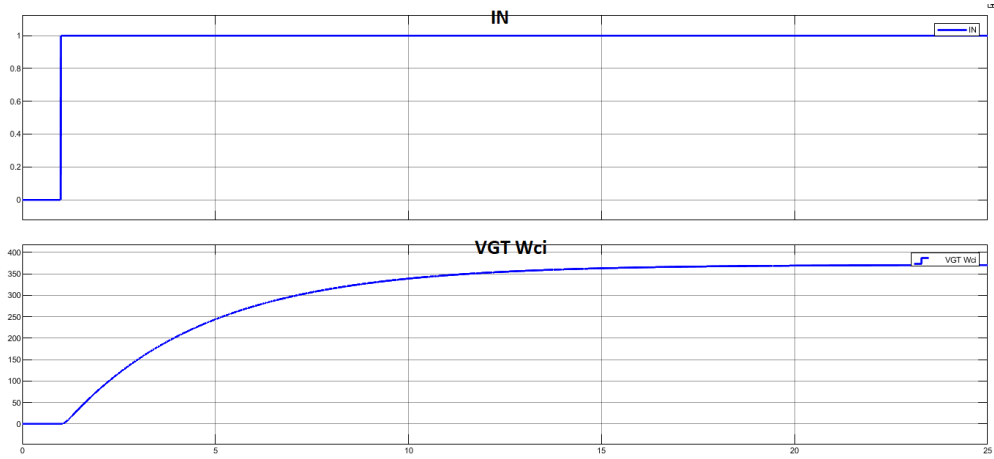

Fig. 3. Minimal realization of VGT- $W_{c i}$ transfer step response

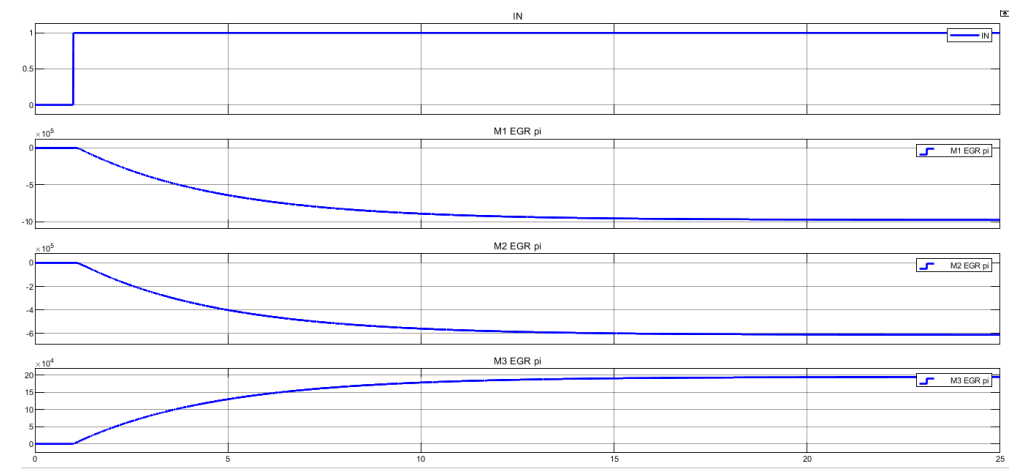

Fig. 4. Multi-model minimal realization of EGR- $p_{i}$ transfer step response

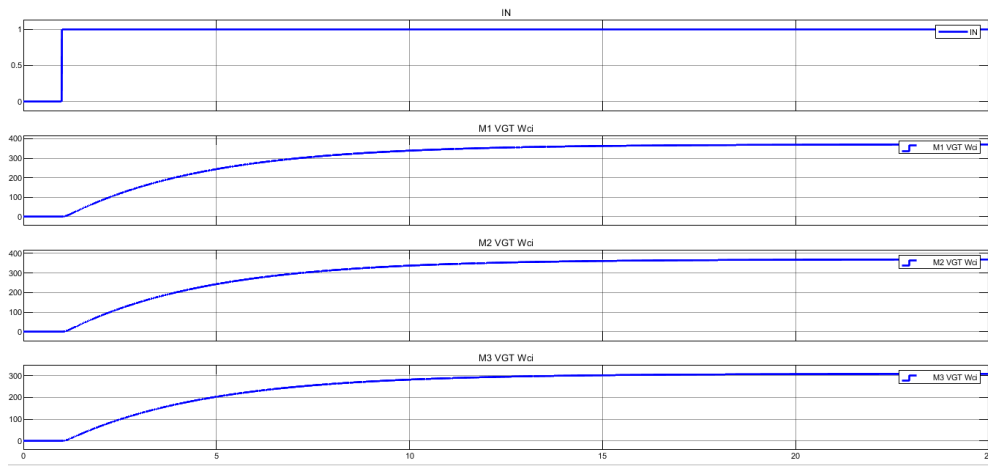

Fig. 5. Minimal realization of VGT- $W_{c i}$ transfer step response

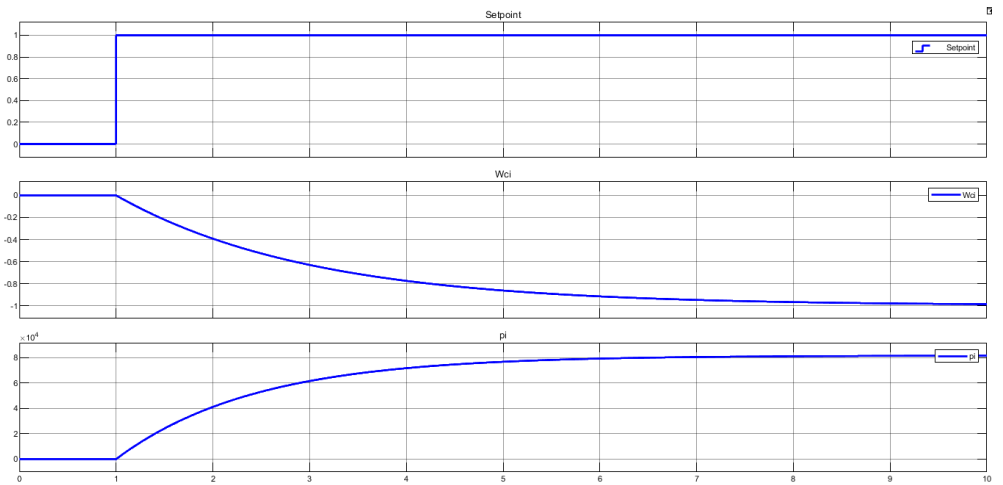

Fig. 6. Optimal control step response

[6] S. Samokhin and K. Zenger, "High-pressure recirculated exhaust gas fraction estimation and control in marine diesel engines", IEEE, 978-14799-7886-1, 2016.

[7] A. Trofino Neto, L. Dugard, J. M. Dion, "Robustness of uncertain linear systems via L. Q. regulators with state estimation", 12th IFAC World Congress, Sydney, Australia, pp. 305-308, 1993.

[8] A. Trofino Neto, L. Dugard, J. M. Dion, "Robustness bounds for LQ regualtors“, IEEE Trans. Aut. Contr., vol. 37, pp. 1373-1377, 1992.

[9] A. Oustaloup, "La robustesse. Analyse et synthese de commandes robustes“, Edition Hermes, 1994

[10] P. P. Khargonekar, M. A. Rotea, "Stabilisation of uncertain linear systems with norm-bounded uncertainly using control Lyapunov functions“, Proc. 27th Conf. Decision Contr., Austin, Texas, pp. 503-507, 1988.

[11] P. P. Khargonekar, I. R. Petersen, K. Zhou, "Robust stabilization of uncertain linear systems: Quadratic stabilizability and $H_{\infty}$ Control Theory“, IEEE Trans. Automat. Contr., vol. AC-35, pp. 356-361, 1990.

[12] J. C. Doyle and G. Stein, "Multivariable feedback design: concept for classical/modern synthesis“, IEEE Trans. Automat. Contr., AC-26, pp. 4-16, 1981.

[13] R. E. Kalmna, "Contributions to the theory of optimal control", Bol. Soc. Mat. Mex., 5, pp. 102-119, 1961.

[14] F. Hamidi, H. Jerbi, M.N. Abdkrim, "Enlarging the robust domain of attraction in nonlinear polynomial uncertain systems", Proc. IASTED Int. Conf. on Control and Applications, p.729-738, 2012. 